\title{
Téoros
}

Revue de recherche en tourisme

\section{Analyse du potentiel touristique du patrimoine religieux montréalais}

\section{Sylvie Blais et Pierre Bellerose}

Volume 16, numéro 2, été 1997

Tourisme et religion

URI : https://id.erudit.org/iderudit/1074579ar

DOI : https://doi.org/10.7202/1074579ar

Aller au sommaire du numéro

Éditeur(s)

Université du Québec à Montréal

ISSN

0712-8657 (imprimé)

1923-2705 (numérique)

Découvrir la revue

Citer cet article

Blais, S. \& Bellerose, P. (1997). Analyse du potentiel touristique du patrimoine religieux montréalais. Téoros, 16(2), 38-40. https://doi.org/10.7202/1074579ar d'utilisation que vous pouvez consulter en ligne. 


\section{AnAlyse DU POTENTIEL TOURISTIQUE DU PATRIMOINE RELIGIEUX MONTRÉALAIS}

\author{
Sylvie Blais \\ Ministère de la Culture et des Communications du Québec \\ Pierre Bellerose \\ Office des congrès et du tourisme du Grand Montréal
}

Nos églises, notre plus grande richesse patrimoniale, sont aussi les témoins privilégiés de toute l'histoire du développement de Montréal et du Québec. Plusieurs de ces trésors du patrimoine, souvent centenaires, sont protégés par le ministère de la Culture et des Communications. En effet, presque la moitié $(47 \%)$ des biens culturels protégés en vertu de la Loi sur les biens culturels font partie du patrimoine religieux du Québec ; c'est dire l'importance de cet héritage, en termes d'édifices, de biens mobiliers et d'auvres d'art, et son enracinement au Québec.

Parmi les biens protégés liés au patrimoine religieux, on trouve 221 bâtiments, non seulement des églises, mais aussi des presbytères, des chapelles, des sanctuaires, 51 calvaires et croix de chemin, 22 cimetières et charniers, 53 collections d'œuvres d'art religieux et 60 fonds d'archives.

Au-delà de ces monuments historiques, on peut dénombrer au Québec un total d'environ 1100 églises catholiques construites avant 1945 ; on considère qu'au moins la moitié d'entre elles ont une valeur patrimoniale. Les autres traditions religieuses regroupent environ 375 temples, les plus anciens ayant été érigés dans la première moitié du XIXe siècle. II y a au Québec 49 endroits - musées, lieux historiques et centres d'interprétation - dont l'objectif principal est la mise en valeur du patrimoine religieux.

Mais, qu'ils soient classés ou non, ces lieux de culte coûtent extrềmement cher à entretenir et à rénover, alors que les insti- tutions religieuses n'ont plus les mêmes ressources que par le passé.

La pratique religieuse, qui a énormément diminué au cours des dernières décennies, est l'un des faits marquants de cette crise que vivent les institutions religieuses présentement. Selon un sondage Gallup, $31 \%$ des Canadiens disent être allés à l'église, à la synagogue ou dans un autre lieu de culte dans les sept jours précédant le sondage, en avril 1995. Cette diminution des pratiquants a des répercussions importantes sur le financement des églises qui doivent se tourner vers de nouvelles avenues.

Tout en permettant à plusieurs églises de poursuivre parallèlement leur vocation première, la fréquentation de sites patrimoniaux religieux par une clientèle touristique peut être un moyen intéressant de développer un achalandage nouveau, d'accroitre l'intérêt et de créer des liens de nature économique avec des intervenants.
Ce potentiel touristique est d'autant plus prometteur que des efforts importants ont été déployés afin de restaurer ce patrimoine.

À cet effet, en octobre 1995, la ministre de la Culture et des Communications du Québec, $\mathrm{M}^{\mathrm{m}=}$ Louise Beaudoin, lance un programme qui a un effet mobilisateur et déterminant pour la conservation et la mise en valeur du patrimoine religieux. Il s'agit du Programme d'aide à la restauration du patrimoine religieux, dans lequel le gouvernement prévoit investir au total près de 45 millions de dollars sur cinq ans.

L'un des premiers effets du lancement de ce programme est de donner lieu à la création d'un organisme sans but lucratif, à caractère multiconfessionnel, euvrant à l'échelle du Québec à la conservation du patrimoine religieux : la Fondation $d u$ patrimoine religieux du Québec. Inspirée par le modèle de l'organisme Pierres vivantes - Living Stones qui, sur l'Île de Montréal cuvrait déjà depuis 1992, la Fondation regroupe des représentants de toutes les traditions religieuses : catholique, anglicane, protestante, juive... Elle a comme mission d'aider les communautés à assurer la conservation et la mise en valeur de leurs biens patrimoniaux et d'assurer la gestion du programme.

Pour la première fois au Québec, on assiste à la mise en place d'une structure nationale bien organisée, pourvue des moyens financiers nécessaires à une action significative, à moyen terme, sur la question du patrimoine religieux.

Le fonctionnement de la Fondation du patrimoine religieux du Québec est 


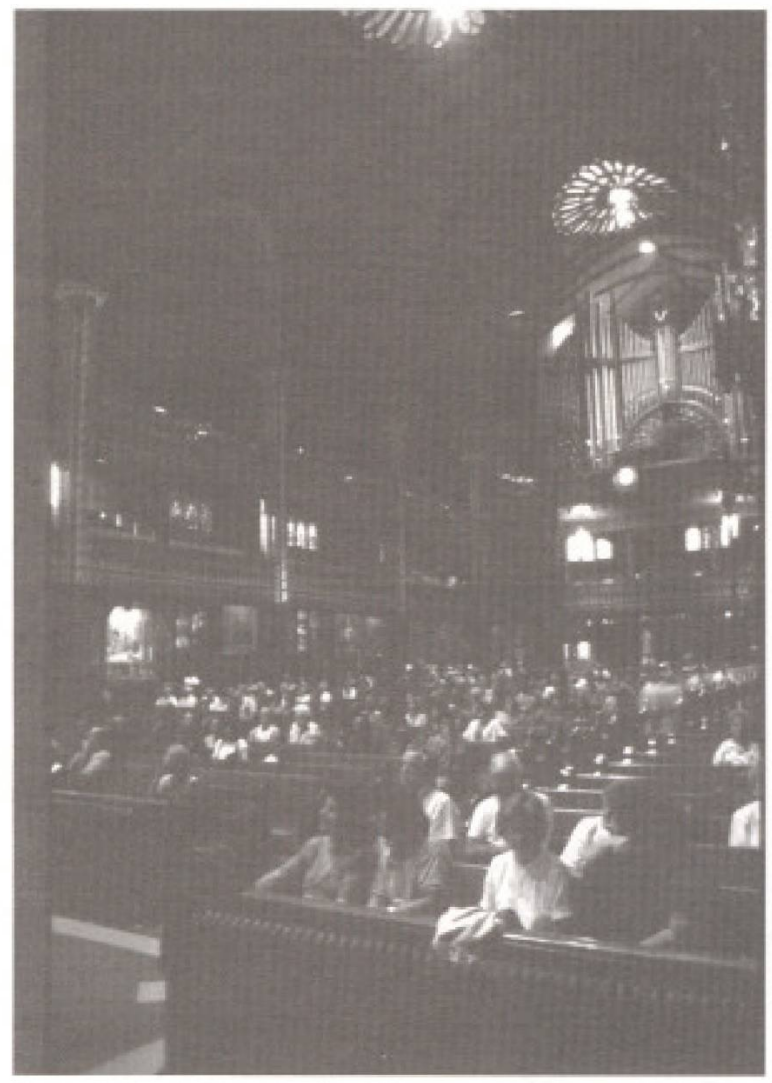

Basilique Notre-Dame, Montréal.

décentralisé ; onze groupes de travail répartis dans autant de régions - Tables et sous-tables de concertation régionales - réunissent des représentants des communautés religieuses et du ministère de la Culture et des Communications, ainsi que des personnes-ressources du milieu privé. Dans ce dernier cas, il peut s'agir d'historiens, d'architectes, d'urbanistes, de conservateurs de musées, de professeurs d'université, d'historiens de l'art, d'ethnologues, bref, différents spécialistes susceptibles d'apporter aide et conseils aux tables.

Sur l' Île de Montréal, au moment de l'annonce du programme, une première évaluation du nombre de bâtiments religieux susceptibles d'être concernés a permis de dénombrer environ 160 bâtiments églises, temples, presbytêres, synagogues - construits avant 1945 qui présentent un intérêt patrimonial.

La formation de la Table régionale pour Montréal a permis de réunir 16 personnes ; c'est la plus importante au Québec. La plupart ceuvrent dans le domaine de la sauvegarde du patrimoine religieux depuis de nombreuses années, dont deux représentants du ministère de la Culture et des Communications.

En février dernier, le bilan du programme permettait d'établir que près de 3 millions de dollars avaient été approuvés pour des subventions de près de 2 millions, une partie des fonds provenant de contributions privés. Sur 21 projets approuvés, 9 sont déjà complétés. Restauration de toitures, réparation de maçonnerie, travaux divers aux clochers, restauration d'intérieurs sont autant d'exemples des projets réalisés.

A titre d'exemples, soulignons, au centre-ville et dans le Vieux-Montréal : Chapelle de l'Invention des Soeurs Grises, les églises St. Andrew and St. Paul et Saint-PierreApôtre, ainsi que la chapelle Notre-Dame-de-Bonsecours, où d'importants travaux seront complétés au printemps 1998.

\section{PATRIMOINE RELIGIEUX MONTRÉALAIS : UNIQUE ET RÉVÉLATEUR}

Une réflexion effectuée par l'Office des congrès et du tourisme du Grand Montréal en 1995 a permis l'analyse d'une trentaine d'éléments importants du patrimoine religieux des quartiers centraux de Montréal. Cette étude a dressé un portrait assez exhaustif des éléments déjà connus (Basilique Notre-Dame, Oratoire Saint-Joseph, Cathédrale MarieReine-du-Monde, Cathédrale protestante Christ-Church) ou à découvrir (église St. James The Apostle, chapelle NotreDame-de-Lourdes, etc.).

Cette analyse des bâtiments religieux concentrés dans les pôles touristiques de Montréal a permis de dresser une vue d'ensemble du patrimoine religieux, de sa richesse historique et architecturale. Plusieurs églises sont accessibles aux touristes, surtout pendant la période estivale. De plus, il n'est pas rare que des concerts s'organisent, sur une base régulière ou occasionnelle, beaucoup de nos églises étant dotées d'orgues de grande qualité et d'une acoustique exceptionnelle.

La période de Noël est particulièrement intense en activités d'animation comme des visites de crèches de Noël et des concerts. Certains organismes, dont Héritage Montréal, Guidatour et Tour Ecclesia, organisent déjà des circuits de visites dans les églises.

Selon l'Office des congrès et du tourisme du Grand Montréal (OCTGM), il existe actuellement un marché et un intérêt réel, quoique limité, à visiter les églises les plus imposantes du grand centre-ville. Il est intéressant de constater que $10,4 \%$ de toutes les demandes d'information touristique du principal kiosque frontalier (Lacolle) portaient exclusivement sur les eglises.

A la suite de l'analyse de ce produit, l'OCTGM en est venu à la conclusion que le patrimoine religieux montréalais a des caractéristiques propres qui, bien mises en Évidence, seraient en mesure d'attirer un nombre beaucoup plus important de visiteurs. Voici les principaux constats qui ressortent de cette évaluation :

\section{CONCENTRATION HISTORIQUE}

L'analyse des différentes fiches techniques réalisées dans le cadre de cette étude a permis de constater une concentration très marquée de bâtiments datant de la deuxième partie du $\mathrm{XIX}^{*}$ siècle. En effet, contrairement à d'autres villes du nord-est de l'Amérique du nord (comme Québec et Boston par exemple), on trouve à Montréal peu de traces des périodes précédentes. En fait, près de 25 éléments sur 28 répertoriés se situent entre les années 1830 (basilique Notre-Dame) et 1907 (citadelle de l'Armée du Salut ou Emmanual Congregational). Ainsi, on trouve peu ou pas d'éléments représentatifs de la période mystique de Montréal, caractéristiques du XVIIIe siècle. Les bâtiments de Montréal évoquent plutôt la grande période de prospérité économique qui en font la Métropole du Canada.

\section{ÉMULATION}

Du patrimoine bâti, témoin de notre passé, transcende la réalité sociale de 
l'epoque, marquée par des conflits entre les communautés linguistiques et religieuses. Plusieurs anecdotes reflètent cette confrontation d'idéaux entre les catholiques et les protestants, parfois même ạu sein d'une même communauté religieuse. Par exemple, la cathédrale Marie-Reine-du-Monde a été érigée dans le quartier ouest de Montréal, anglophone et protestant, pour y affirmer le poids de l'église catholique. $\mathrm{M}^{\mathrm{r}}$ Ignace Bourget, porte-parole de l'idéologie ultramontaine de l'époque, choisit comme modèle l'église-mère du catholicisme, SaintPierre-de-Rome. Ce rapport de force entre les congrégations religieuses typiques de cette période a fait en sorte que

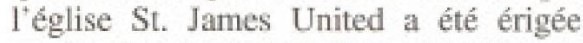
comme la principale église méthodiste de Montréal ; ses dimensions impressionnantes ainsi que son architecture lui conferrent même le titre de Cathédrale de l'église méthodiste. L'église anglicane St. James The Apostle, érigée en plein champ en 1864 , selon un style néo-gothique très populaire à l'époque, voulait aussi démontrer la richesse de la communauté. Les églises du centre-ville de Montréal et les deux cimetières du MontRoyal sont donc le reflet de $1^{t}$ emulation entre les différentes communautés présentes à Montréal au XIXe siècle. Ce patrimoine peut devenir une clé importante de compréhension de l'histoire de Montréal puisqu'aucun élément du patrimoine montréalais ne reflète aussi bien cette réalité historique.

\section{CARACTÈRE UNIQUE EN AMÉRIQUE DU NORD}

La dichotomie culturelle de Montréal, de par la présence des deux communautés fondatrices (anglophone et francophone), a façonné la métropole telle qu'on la connait aujourd'hui. Ce rapport de force entre les communautés linguistiques et religieuses, la diversité des congrégations religieuses au cours de la deuxième partie du XIXe siécle et la concentration des elements religieux pendant ces années-là sont uniques en Amérique du Nord. En effet, on ne trouve cette concentration et cette émulation dans aucune autre ville nord-américaine.

\section{ARCHITECTURE ET ART SACRÉ}

En plus d'offrir des qualités indéniables sur le plan architectural, nos églises pos- sèdent des décors intérieurs d'une grande qualité. En effet, elles ont conservé charme et chaleur que les immenses cathédrales d'Europe, dépouillées de leur mobilier, ont en partie perdus. Certains des objets d'arts réalisés par des artistes de renom sont aussi protégés par la Loi sur les biens culturels du Québec et représentent des trésors trop souvent méconnus. Plusieurs de ces éléments méritent le détour et auraient avantage à être mis en valeur de façon soutenue et concertée.

\section{CONCLUSION}

Notre réflexion a permis de constater que le patrimoine religieux montréalais est un attrait unique et original pour la destination Montréal. En effet, en plus d'offrir des éléments architecturaux et des objets d'art sacrế de très grande qualité, le patrimoine religieux montréalais semble le reflet unique d'une effervescence économique et d'une émulation entre les communautés très caractéristiques de la deuxième moitié du $\mathrm{XIX}^{\mathrm{t}}$ siècle.

En ce sens, et sur plus d'un plan, nous avons la conviction que le patrimoine religieux montréalais peut accroitre son rayonnement auprès des clientèles internationales.

Toutefois, il ne faut pas sous-estimer la complexité de l'industrie touristique. En effet, le tourisme est un univers multiforme et complexe, il s'adresse autant aux concierges d'hôtels qu'aux grossistes européens, aux guides touristiques qu'aux organisateurs de congrès, aux chauffeurs de taxi qu'à l'Office des congrès et du tourisme du Grand Montréal (OCTGM).

De plus, chaque secteur du tourisme (voyages individuels ou en groupe, voyages-motivation, congrès, etc.) a son propre réseau de distribution qui est souvent cloisonné. Aussi, comme dans d'autres champs d'activités, les clients (et leur façon de voyager) évoluent rapidement.

Pour accroitre la fréquentation des sites religieux, il faut travailler tant sur le produit que sur les clientèles. Voici, en résumé, les actions à poser pour atteindre cet objectif :

1. Mettre en évidence la cohêrence historique du patrimoine religieux montréalais plutôt que des éléments isolés.
2. Bien renseigner, grâce à l'information des fiches techniques, le réseau d'accueil montréalais et les grossistes réceptifs (en les invitant, entre autres, sur place).

3. Raffermir les contacts privilégiés avec l'industrie touristique montréalaise.

4. S'assurer qu'une organisation coordonne les efforts des responsables des différents sites religieux et devienne l'interlocutrice des différents intervenants touristiques.

5. S'assurer d'un accueil de qualité (horaire, interprétation, guides, etc.) dans les principaux sites religieux.

6. Continuer la réflexion sur les clientèles (touristiques) des sites religieux montréalais, surtout en ce qui concerne l'information de base.

Le défi est grand puisque de nombreux intervenants culturels (musées, événements, acteurs dans le secteur du patrimoine, etc.) s'engagent de façon importante auprès des clientèles et des intervenants touristiques. Dans les faits, de plus en plus de gestionnaires du milieu culturel sollicitent les mêmes intervenants et les mêmes touristes.

Les responsables des sites religieux devront faire preuve d'une réelle volonté d'action et de créativité si l'on veut s*assurer que le patrimoine religieux montréalais ne demeure encore longtemps le plus beau secret caché de Montréal.

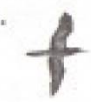

\section{BIBLIOGRAPHIE}

Bellerose, Pierre, et Évelyne Dubourg (1995), Etude sur le potentiel touristique du patrimoine religieur montréalais, OCTGM, août. 